\title{
Biomass from Paddy Waste Fibers as Sustainable Acoustic Material
}

\author{
A. Putra, Y. Abdullah, H. Efendy, W. M. F. W. Mohamad, and N. L. Salleh \\ Sustainable Maintenance Engineering Research Group, Faculty of Mechanical Engineering, Universiti Teknikal Malaysia Melaka, \\ Hang Tuah Jaya, 76100 Durian Tunggal, Malacca, Malaysia \\ Correspondence should be addressed to A. Putra; azma.putra@utem.edu.my
}

Received 31 March 2013; Revised 5 August 2013; Accepted 8 August 2013

Academic Editor: Rama Bhat

Copyright (C) 2013 A. Putra et al. This is an open access article distributed under the Creative Commons Attribution License, which permits unrestricted use, distribution, and reproduction in any medium, provided the original work is properly cited.

Utilization of biomass for green products is still progressing in the effort to provide alternative clean technology. This paper presents the utilization of natural waste fibers from paddy as acoustic material. Samples of sound absorbing material from paddy waste fibers were fabricated. The effect of the fiber density, that is, the fiber weight and the sample thickness, and also the air gap on the sound absorption coefficient is investigated through experiment. The paddy fibers are found to have good acoustic performance with normal incidence absorption coefficient greater than 0.5 from $1 \mathrm{kHz}$ and can reach the average value of 0.8 above $2.5 \mathrm{kHz}$. This result is comparable against that of the commercial synthetic glass wool. Attachment of a single layer of polyester fabric is shown to further increase the absorption coefficient.

\section{Introduction}

Use of synthetic porous and fibrous acoustic materials is still frequently found especially in building acoustics as well as in noise control applications. The products such as foam, rock wool, and glass wool made from minerals are known for their toxicity and polluting effects which are harmful to human health as well as to the environment. It has been presented that their production can release more carbon dioxide into the atmosphere compared to those made from natural materials [1]. In order to support "green" environment campaign, acoustic absorbers from natural materials are therefore of interest due to their biodegradability and sustainability.

Several works have been published which studied the potential of natural materials to be employed as sound absorbing materials. The bamboo fibers are found to have absorption coefficient similar to that of the commercial glass fiber. The fibers were also used to develop a fiber board of a resonant-type absorber and are found to have better acoustic performance compared to plywood [2].

The sound absorption of kenaf fibers was investigated by D'Alessandro and Pispola [3] through a reverberant room test showing absorption coefficient of 0.85 above $1 \mathrm{kHz}$. Ersoy and Küçük [4] studied the potential of waste industrial tea leaf and found that the absorption coefficient of the waste fibers increases significantly when backed with a single woven cotton cloth. For $10 \mathrm{~mm}$ thickness, the acoustic performance of the tea leaf fiber at high frequency is superior to that of polyester and polypropylene.

Waste ramie fibers treated and nontreated with alkalization can also produce promising results with an average absorption coefficient of 0.6 at frequency range of $500 \mathrm{~Hz}-$ $3.2 \mathrm{kHz}$ [5]. Comprehensive studies on panels made from coir fibers have been conducted to investigate the effect of perforated facing, multiple-layer arrangement, and the panel compression on the acoustic performance [6-8]. Overall, coir fiber is a naturally good sound absorber at medium to high frequency at $1.5-5 \mathrm{kHz}$.

Investigation on the acoustic properties of Arenga pinnata fibers which can be found from a palm sugar tree has been reported [9]. These are the type of hard fibers which are similar to the coir fibers. Usually this type of fiber starts to perform at frequency range higher than that of the soft fibers. The normal incidence absorption coefficient can reach $0.75-$ 0.85 at frequency between 2 and $5 \mathrm{kHz}$ with sample thickness of $40 \mathrm{~mm}$. Jute fibers have also been tested to have potential acoustic absorptivity [10]. The flammability properties are also found to be better than a commercial sound absorber. 


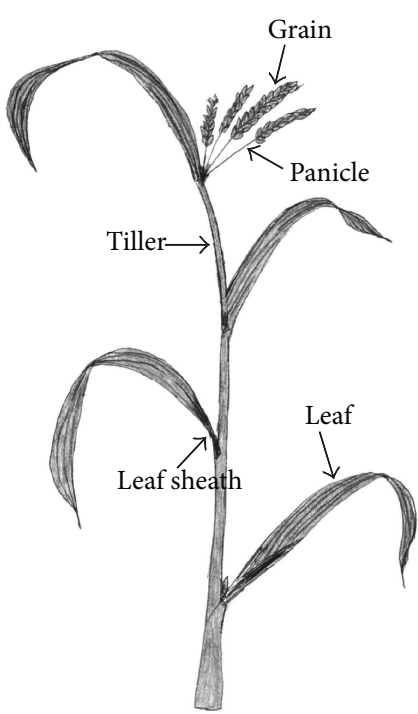

(a)

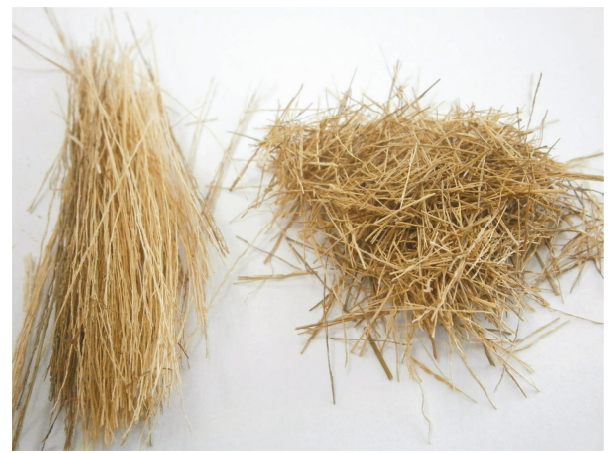

(b)

FIGURE 1: (a) External anatomy of rice paddy and (b) raw paddy fibers from the panicles.

Most recently, Putra et al. [11] presented the acoustic performance of fibers from sugarcane bagasse. Normal incidence test shows the fibers to have good absorption coefficient above 0.5 from $1 \mathrm{kHz}$. At $2-4.5 \mathrm{kHz}$, the average absorption coefficient is 0.8 . Comparable result of sound absorption with fiber glass was also shown. Sound absorber panel constructed from various vegetable fibers including coconut, palm, sisal, and açaí was presented by Bastos et al. [12]. Measurement inside a scaled reverberation chamber reveals promising results of sound absorption performance for all the panels. The samples also underwent flammability, odor, fungal growth, and ageing tests to identify their capability in practical situation.

The acoustic properties of nonfibrous type materials were studied by Oldham et al. [13]. The wastes from straw and reed were investigated by utilizing their hollow structures to trap the sound wave. Quite promising results are presented where the materials can absorb sound effectively from low to high frequency ranges at $500 \mathrm{~Hz}-5 \mathrm{kHz}$. The prediction model is also proposed.

This paper presents the investigation of the waste fiber from rice paddy for its capability to be a sound absorbing material, which according to the author's knowledge has not been addressed or is rarely discussed by other researches. For this purpose, raw materials from the paddy fibers were fabricated into samples which can be measured through an impedance tube test for their normal incidence sound absorption coefficient.

\section{Preparation of the Materials}

2.1. Paddy Fibers. Paddy or Oryza sativa is known for its seed or grain called rice as the main source of meal especially in Asia. Rice is still the most consumed food grain in the world with total consumption of 444 million metric tons in
2011 according to the US Department of Agriculture [14]. Southeast Asia, including Thailand and Vietnam is among the biggest producers and exporters of rice in the world.

The cultivation of rice yields two main important types of residues: husk and straw. One ton of rice paddy can produce roughly $220 \mathrm{~kg}$ of husk and $290 \mathrm{~kg}$ of straw [15]. Husk is the coating of the paddy grain which is separated from the grain during the milling process. The husk is mainly utilized for power generation where the materials are burnt in boilers or combustion furnaces to produce heat and electricity [16]. The rice straw, on the other hand, is often left in the field and is eventually removed or burned in situ for the next crop. Around 12 million tons of rice straws and wheat straws are burnt annually in Punjab, India [17], in order to save cost for clearing the rice field. This natural waste is sometimes used as food for the ruminants. Studies are being conducted to utilize the rice straw as the bioenergy resource to produce biooil due to its cellulosic property [18]. In Indonesia and Malaysia particularly, the rice straw has long been used to make brooms or mats or other household and handcraft products. It has also been applied for roofs in traditional houses.

Figure 1(a) shows the anatomy of the paddy where the waste straw usually comprises of tiller and panicle [19]. The panicle is a fiber-like structure where groups of flowers or grains grow on top of it. These fibers are presented in Figure 1(b). This paper studies the potential of these panicle fibers to be an alternative acoustic material, where this particular study is rarely found in the literatures. Similar study concerning the paddy waste has been done by Yang et al. [20], but this employed the paddy straws which were processed into particles and were mixed with those from wood to be a wood board that finally has sound absorbing capability. A preliminary study regarding the panicle fibers was conducted by Abdullah et al. [21] where the fibers were mixed with methylcellulose. The binder however can be 


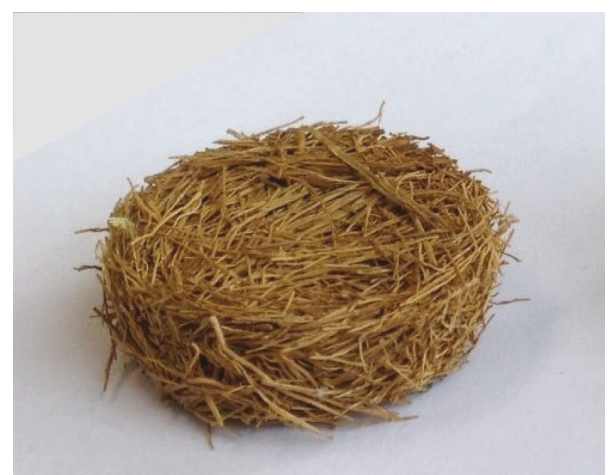

(a)

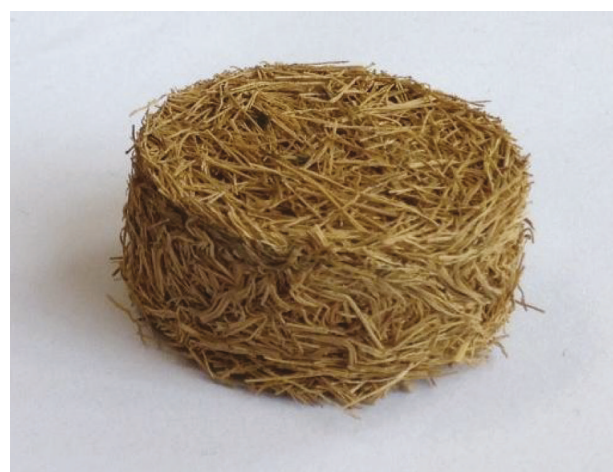

(b)

Figure 2: Examples of fabricated samples from paddy fibers with different thicknesses: (a) $t=10 \mathrm{~mm}, 2$ grams and $\rho_{\text {bulk }}=234 \mathrm{~kg} / \mathrm{m}^{3}$ and (b) $t=20 \mathrm{~mm}, 2$ grams and $\rho_{\text {bulk }}=117 \mathrm{~kg} / \mathrm{m}^{3}$.

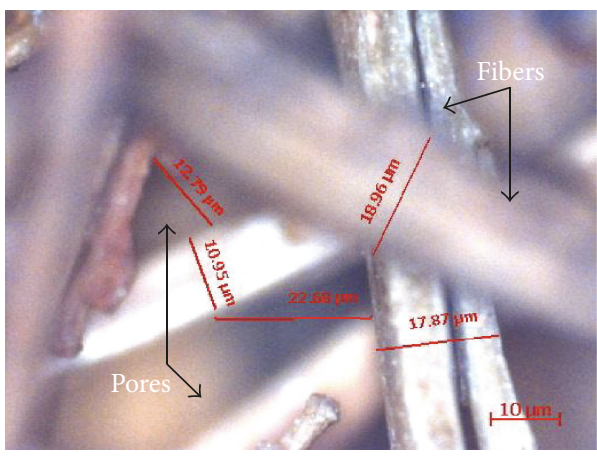

(a)

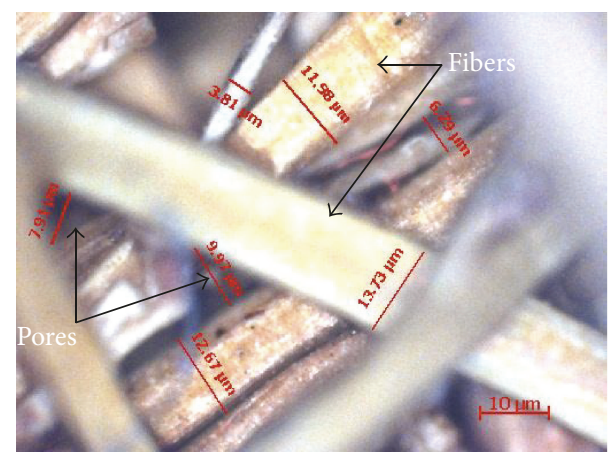

(b)

Figure 3: Microscopic view of samples $(t=20 \mathrm{~mm})$ with different densities: (a) 2 grams and $\rho_{\text {bulk }}=117 \mathrm{~kg} / \mathrm{m}^{3}$ and $(\mathrm{b}) 4 \mathrm{grams}$ and $\rho_{\mathrm{bulk}}=$ $234 \mathrm{~kg} / \mathrm{m}^{3}$ showing the size of the fibers and the pores.

abrasive and is not suitable in practice, although good sound absorption was obtained from the study.

2.2. Fabrication of Absorber Sample. Construction from the paddy fibers into an absorber sample is divided into two stages, namely, the preparation and fabrication stages. In the preparation stage, raw material was dried for one week and then heated in the oven at $80^{\circ} \mathrm{C}$ for 5 minutes to let the remaining water in the fibers evaporate. The raw material was then cut into 5 to $10 \mathrm{~mm}$. In order to have a compact structure, the fibers were then mixed with a binding agent, namely, polyurethane. The composition of the fibers and the binder was roughly $90 \%$ and $10 \%$ by weight, respectively.

In the fabrication stage, the mixtures were hotpressed into a round mold with diameter of $33 \mathrm{~mm}$ to obtain a round shape to fit in the impedance tube during the sound absorption test. Figure 2 shows examples of the fabricated absorber samples with different thicknesses of $10 \mathrm{~mm}$ and $20 \mathrm{~mm}$. For each thickness $t$, the weight of the fiber is given for 2 grams and 4 grams which yields different fiber densities. The bulk density for each sample can be simply calculated by the ratio of the total mass of the sample $M$ and its volume $V$ as $\rho_{\text {bulk }}=M / V$.
Note that the bulk density means the total volume also includes the volume of the pores inside the sample. Measurement using the Inverted Research Microscope (IRM) technique shows that the diameter of the paddy fibers can range from 8 to $20 \mu \mathrm{m}$. Figure 3 shows examples of the microscopic view from samples with thickness of $20 \mathrm{~mm}$ with fiber weight of 2 grams and 4 grams giving different bulk densities. Greater density of sample, that is, more fibers with same thickness, can be seen to have the size of the pores reduced. However, this could form more complicated internal path (tortuosity) which can cause greater sound energy loss.

\section{Measurement of Absorption Coefficient}

3.1. Experimental Setup. Diagram of the measurement setup is shown in Figure 4. The measurement of sound absorption coefficient was conducted using the impedance tube method according to ISO 10534-2:2001 [22]. The sample was placed against a rigid backing at the end of the tube, and a loudspeaker at the other end was used to feed white noise into the tube. Two acoustic microphones, that is, the G.R.A.S $1 / 2$ inch prepolarized free-field microphones type 40AE equipped with $1 / 2$ inch CCP preamplifier type $26 \mathrm{CA}$ were located in 


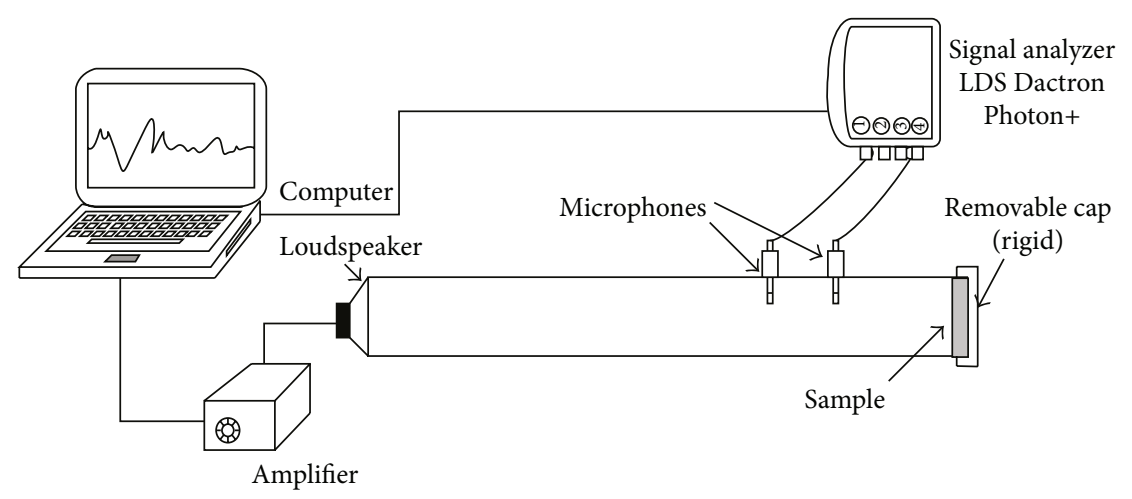

FIGURE 4: Diagram of the measurement setup for the absorption coefficient test.

front of the sample to record the incident sound from the loudspeaker and the reflected sound from the material. The RT Pro Photon+v6.34 analyzer with Dactron software was used as the data acquisition system.

The diameter of the tube used in the experiment is $33 \mathrm{~mm}$ and thus the reliable frequency range is between $500 \mathrm{~Hz}$ and $5 \mathrm{kHz}$. This frequency range corresponds to the diameter of tube accommodating propagation of plane waves for normal incidence assumption. For low frequency below $500 \mathrm{~Hz}$ down to $50 \mathrm{~Hz}$, tube with larger diameter is used to give better accuracy [22]. The recorded signals in the analyzer in terms of the transfer function between the microphones were processed using MATLAB software to obtain the absorption coefficient of the sample under test. All the results are presented here in one-third octave band frequency.

3.2. Results and Discussion. Figure 5 plots the acoustic absorption of 2-gram paddy fibers with different thicknesses of $10 \mathrm{~mm}$ and $20 \mathrm{~mm}$. The result for $10 \mathrm{~mm}$ thick sample shows that good acoustic performance $(\alpha>0.5)$ is achieved at frequency above $3 \mathrm{kHz}$. This is a typical performance of a fibrous absorber, especially a hard-type fiber as also found for the coir fiber, where good sound absorption starts at high frequencies [6]. Doubling the thickness can be seen to increase the absorption coefficient below $3.5 \mathrm{kHz}$, which is also due to reduction of the fiber density [23]. However, reduction of the density also reduces the flow resistivity. Due to the same amount of fibers introduced for the increase volume of the sample, the sample might now have more open pores which allow the sound to propagate easily, especially for high frequency, without having significant viscous losses to convert the sound energy into heat [24]. For the $20 \mathrm{~mm}$ thick sample, the absorption coefficient can be seen to be reduced above $3.5 \mathrm{kHz}$.

To improve the absorption at high frequencies, more fibers can thus be added to increase the density. As seen in Figure 6, by adding the fiber weight to 4 grams, the absorption coefficient increases up to almost 0.9 in average above $3.5 \mathrm{kHz}$. This includes the improvement below this frequency down to $500 \mathrm{~Hz}$.

Figures 5 and 6 compare the results for different fiber densities. It is therefore interesting to investigate the case for

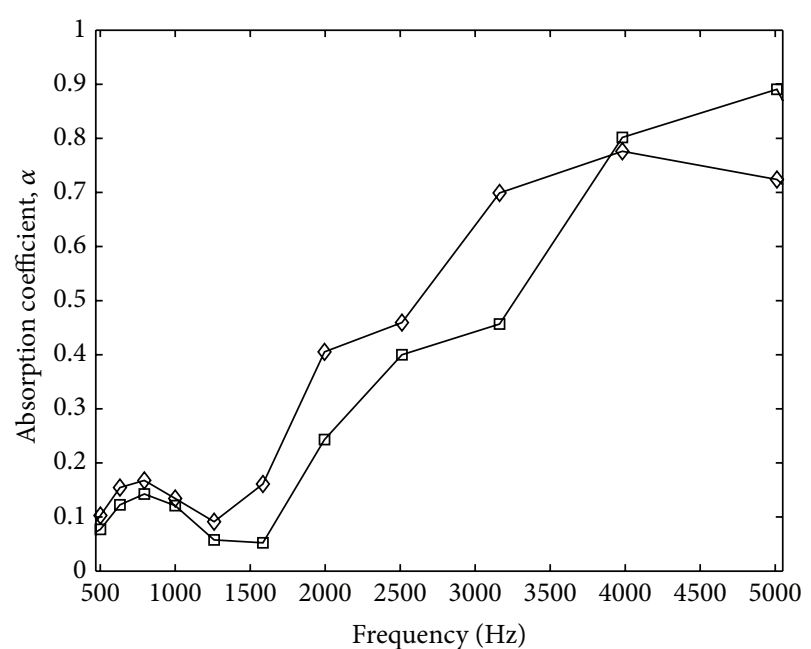

FIGURE 5: Measured absorption coefficient of samples with the same fiber weight of 2 grams: $-\square-t=10 \mathrm{~mm}$ and $-\diamond-t=20 \mathrm{~mm}$.

samples with different thicknesses and fiber weights but the same density as plotted in Figure 7. Here again, the effect of thickness can be seen to consistently increase the absorption coefficient from $500 \mathrm{~Hz}$ without significantly deteriorating the performance at high frequencies, as now the density is kept constant (see again Figure 5).

The effect of density is plotted in Figure 8 . This is done by increasing the fiber weight for a $20 \mathrm{~mm}$ thick sample up to 6 grams. It is interesting to observe here that the measured absorption coefficient has no linear relationship with the density. More fibers can create more tortuous path (increase tortuosity) and can also increase the flow resistivity. However, by further increasing the density (adding more fibers), close pores could be formed and thus greatly increase the flow resistivity and eventually reduce the absorption capability. As seen in Figure 8, the sample with 6-gram fiber weight has lower absorption coefficient than that from the sample with 3-gram fibers. This is consistent with the finding as in [2]. The fabrication process can also have effect on the pores formation inside the sample, for example, during the binder mixing or hot compression. 


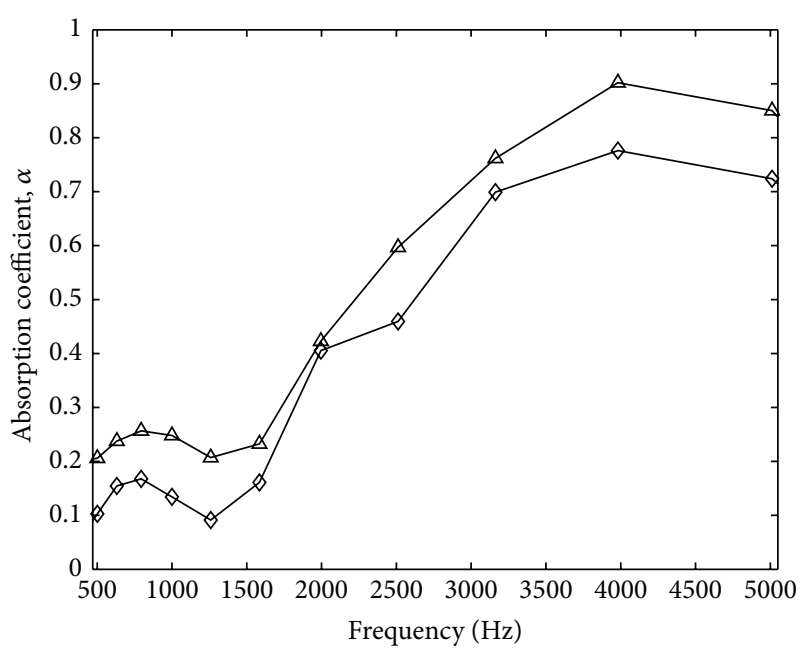

FIGURE 6: Measured absorption coefficient of samples with the same thickness, $t=20 \mathrm{~mm}$ : $-\diamond-2$ grams and $-\triangle-4$ grams.

Improvement of sound absorption at low frequencies can also be achieved by adding an air layer behind the absorber, that is, by moving away the absorber panel from the rigid wall at a certain distance $D$. Figure 9 shows the effect of introducing the air layer on the measured absorption coefficient. The absorption coefficient can be seen to shift to lower frequencies as the air gap distance is increased. A maximum peak can also be observed for each corresponding air layer depth which, for a thin panel, corresponds to a quarter acoustic wavelength where the velocity of the air particle is at maximum on the surface of the absorber [25]. The phenomenon may differ for a thick sample as in this case, but the frequency of the maximum peaks is shown to be the same for both sample thicknesses which indicates the relation of the peak frequency with the air layer depth. The absorption coefficient after the peak can be seen to decay towards the minimum peak or dip due to the formation of multiple peaks at higher frequencies.

The results in Figure 9 also show interesting phenomenon where introducing the air layer to the sample with greater density, that is, $10 \mathrm{~mm}$ thick sample (Figure 9(a)), yields greater sound absorption effect. For the sample with greater density of fiber, the sound passing through the sample might be trapped longer in the air gap causing more energy loss compared to that with smaller density.

In practice the fibrous absorber may not be directly exposed to sound but is covered by a layer for protection or artistic purpose, Here a polyester fabric from a textile cloth was used and was attached on the front surface of the sample, on the back surface, and on both the front and back surfaces as seen in Figure 10. The measurement results are shown in Figure 11. It is found that covering the facing of the sample with the polyester fabric gives substantial improvement to the sound absorption especially from $1.2 \mathrm{kHz}$ to $3.2 \mathrm{kHz}$. The absorption coefficient almost reaches unity at $2-3 \mathrm{kHz}$.

Covering only the back surface also increases the absorption coefficient below $3 \mathrm{kHz}$. Similar trend is also found in [4]. Further improvement at lower frequencies below $2 \mathrm{kHz}$

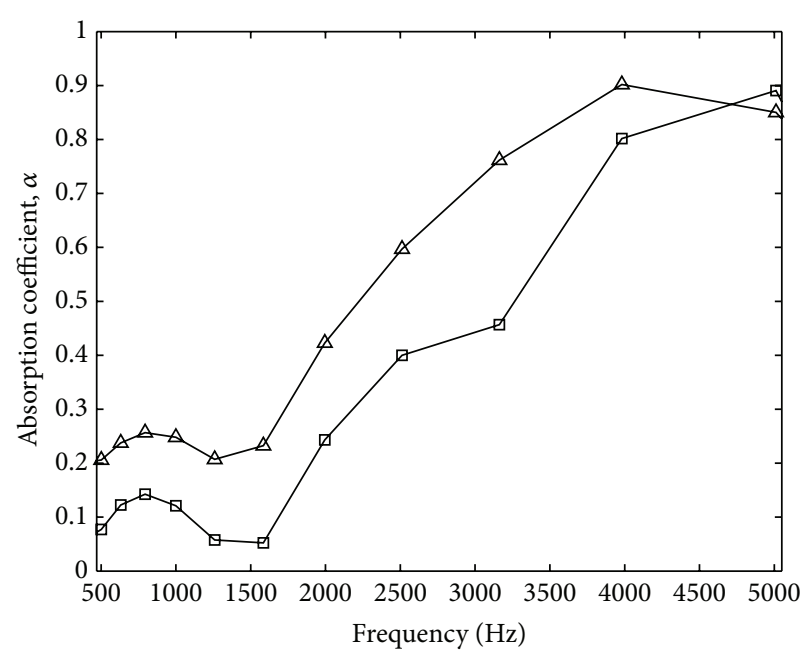

FIGURE 7: Measured absorption coefficient of samples with the same density, $\rho_{\text {bulk }}=234 \mathrm{~kg} / \mathrm{m}^{3}:-\square-t=10 \mathrm{~mm} ; 2$ grams and $-\triangle-$ $t=20 \mathrm{~mm} ; 4$ grams.

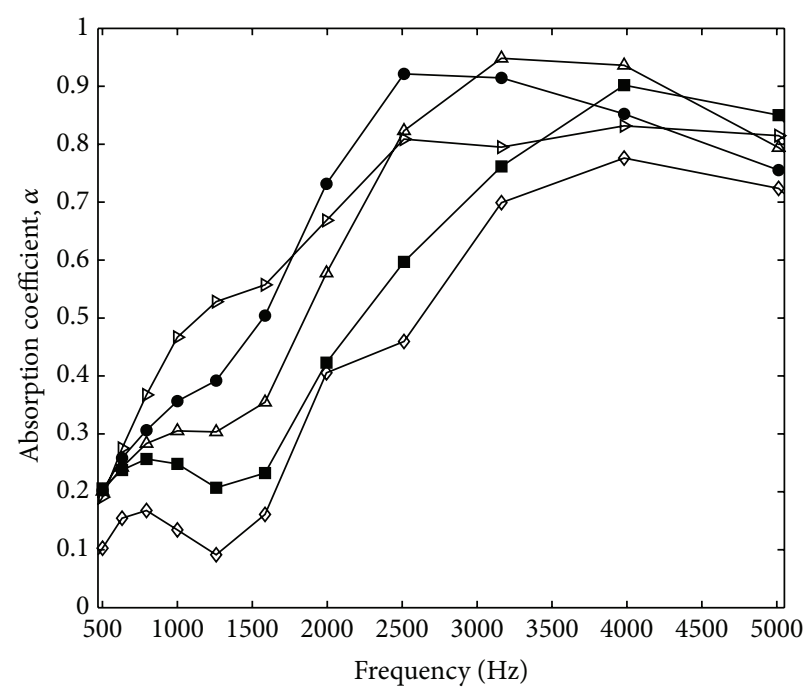

FIGURE 8: Measured absorption coefficient of $20 \mathrm{~mm}$ thick samples with different fiber weights: $-\diamond-2$ grams, $\longrightarrow-3$ grams, $-\triangle-$ 4 grams, $-\bullet-5$ grams and $-\mathbf{-}-6$ grams.

can be seen when the polyester fabric was attached on both surfaces of the sample.

Figure 12 compares the absorption coefficient of the sample having 3 grams of fiber weight with that of glass wool of thickness 0.75 inch $\approx 20 \mathrm{~mm}$. Comparable sound absorption performance with the commercial glass wool can be observed, although the latter shows its superior performance at high frequencies above $3 \mathrm{kHz}$. This, however, demonstrates that the paddy fiber can be a good alternative green and sustainable acoustic material.

\section{Conclusion}

Samples of sound absorber from paddy waste fibers have been tested for their sound absorption performance, and the 


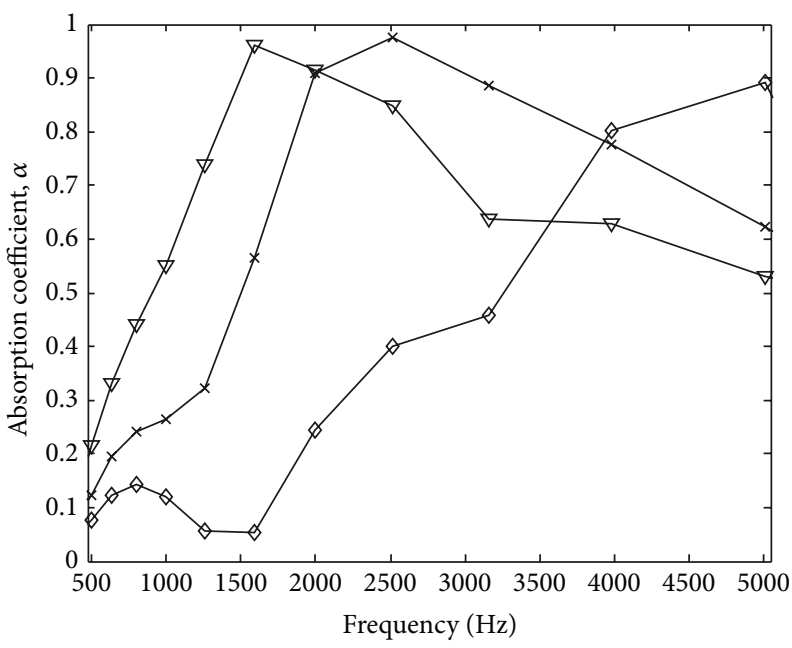

(a)

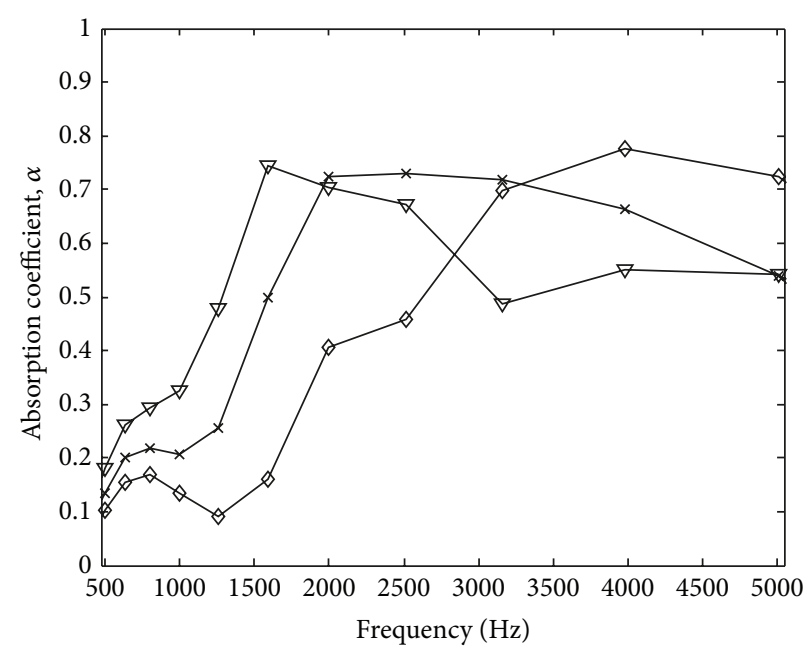

(b)

Figure 9: Measured absorption coefficient of 2 gram samples with thickness of (a) $10 \mathrm{~mm}$ and (b) $20 \mathrm{~mm}$ with different backed air layer thicknesses: $-\diamond-$ without air layer, $-\times-D=10 \mathrm{~mm}$, and $-\nabla-D=20 \mathrm{~mm}$.

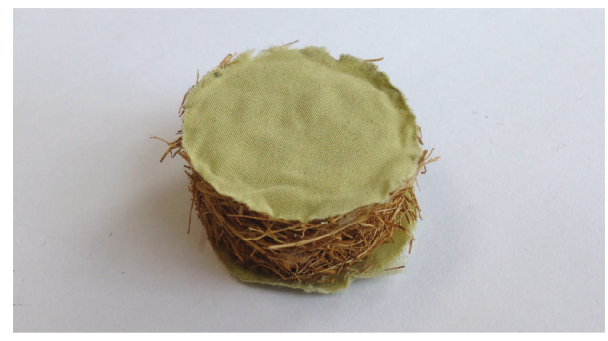

FIGURE 10: Sample of the paddy fiber attached with polyester fabric.

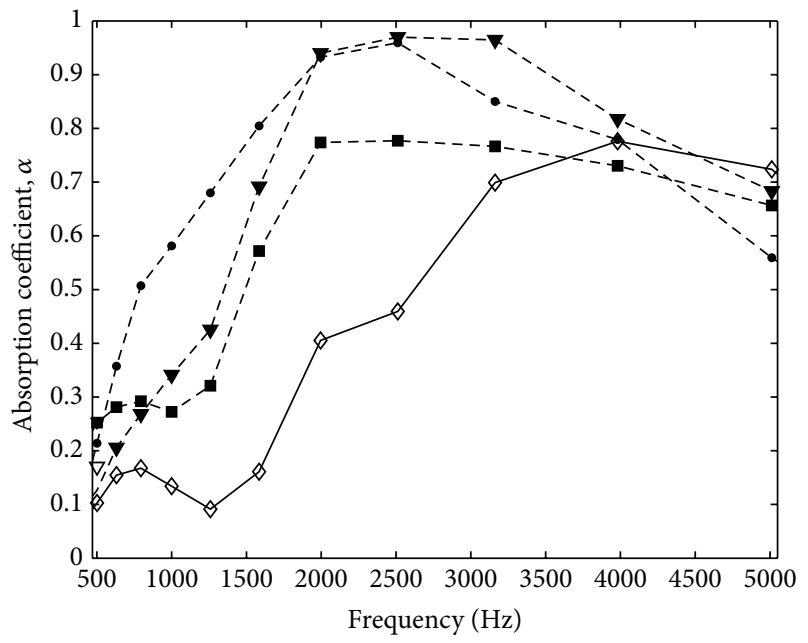

FIGURE 11: Measured absorption coefficient of sample $(t=20 \mathrm{~mm}, 2$ grams) with polyester fabric: $-\diamond-$ without, $-\nabla-$ on front surface, - - on back surface, and - • - on front, and back surfaces.

measured normal incidence absorption coefficient has been reported. The experimental results show that this natural fiber can be utilized as a potential alternative acoustic material.

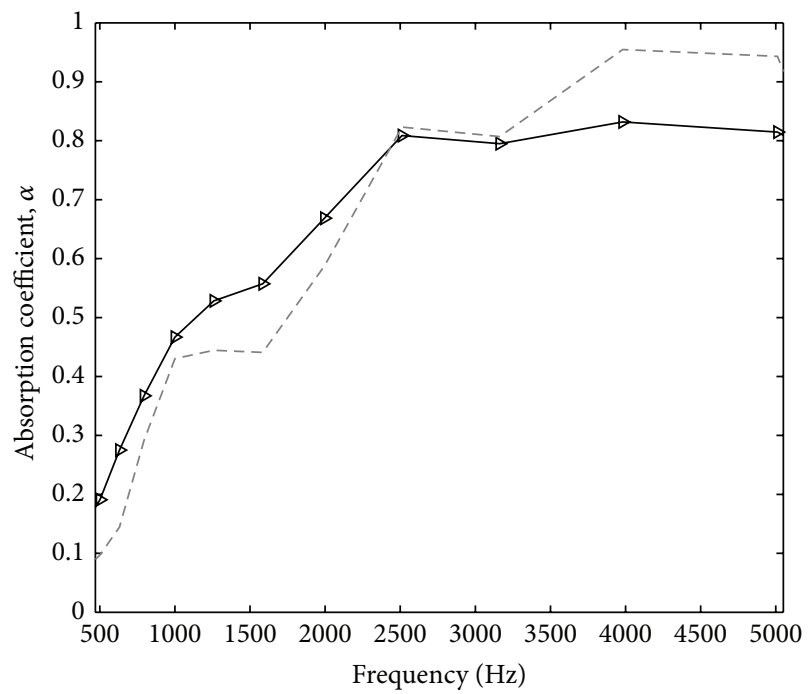

FIGURE 12: Comparison of absorption coefficient of the paddy fiber sample ( $\longrightarrow-t=20 \mathrm{~mm}, 3$ grams) with that from the commercial glass wool (- - ).

With thickness of $20 \mathrm{~mm}$ and 3 grams of fiber weight, the absorption coefficient is more than 0.5 above $1 \mathrm{kHz}$ and can reach 0.8 on average above $1.5 \mathrm{kHz}$, comparable with the performance of a synthetic glass wool with the same thickness. By introducing a single layer of polyester fabric to the sample's facing, further improvement of sound absorption can be obtained. It has also been discussed that care has to be taken when designing the density of the absorber, as too dense fibers can deteriorate the sound absorption performance. In order to fully confirm the robustness of paddy waste fibers in practice, additional environmental tests are required, for examples the fire retardant, fungal growth and humidity tests which are of interest in the extension of this current work. 


\section{Symbols}

$$
\begin{array}{ll}
t: & \text { Sample thickness }(\mathrm{m}) \\
\rho_{\text {bulk }}: & \text { Bulk density }\left(\mathrm{kg} / \mathrm{m}^{3}\right) \\
D: & \text { Air layer thickness }(\mathrm{m}) \\
\alpha: & \text { Absorption coefficient. }
\end{array}
$$

\section{Disclosure}

The authors declare that no financial relation exists either directly or indirectly between the authors and the commercial entities mentioned in the paper.

\section{Acknowledgment}

The financial support for this project is provided by the Ministry of Higher Education, (MoHE), Malaysia under the Fundamental Research Grant Scheme no. FRGS/2010/FKM/ SG03/7-F00095.

\section{References}

[1] F. Asdrubali, "Survey on the acoustical properties of new sustainable materials for noise control," in Proceedings of the Euronoise, Tampere, Finland, 2006.

[2] T. Koizumi, N. Tsujiuchi, and A. Adachi, "The development of sound absorbing materials using natural bamboo fibers," High Performance Structures and Materials, vol. 4, pp. 157-166, 2002.

[3] F. D'Alessandro and G. Pispola, "Sound absorption of sustainable fibrous materials in an enhanced reverberation room," in Proceedings of the Congress and Exposition on Noise Control Engineering, 2005.

[4] S. Ersoy and H. Küçük, "Investigation of industrial tea-leaffibre waste material for its sound absorption properties," Applied Acoustics, vol. 70, no. 1, pp. 215-220, 2009.

[5] R. Eriningsih, "Flax fiber composites and hemp waste as a sound absorption material," Arena Textiles, vol. 24, pp. 51-59, 2009 (Indonesian).

[6] R. Zulkifli, Z. Zulkarnain, and M. J. M. Nor, "Noise control using coconut coir fiber sound absorber with porous layer backing and perforated panel," The American Journal of Applied Sciences, vol. 7, no. 2, pp. 260-264, 2010.

[7] M. H. Fouladi, M. J. M. Nor, M. Ayub, and Z. A. Leman, "Utilization of coir fiber in multilayer acoustic absorption panel," Applied Acoustics, vol. 71, no. 3, pp. 241-249, 2010.

[8] M. J. M. Nor, M. Ayub, R. Zulkifli, N. Amin, and M. H. Fouladi, "Effect of different factors on the acoustic absorption of coir fiber," Journal of Applied Sciences, vol. 7, pp. 1285-1290, 2010.

[9] L. Ismail, M. I. Ghazali, S. Mahzan, and A. M. A. Zaidi, "Sound absorption of Arenga Pinnata natural fiber," World Academy of Science, Engineering and Technology, vol. 67, pp. 804-806, 2010.

[10] S. Fatima and A. R. Mohanty, "Acoustical and fire-retardant properties of jute composite materials," Applied Acoustics, vol. 72, no. 2-3, pp. 108-114, 2011.

[11] A. Putra, Y. Abdullah, H. Efendy, W. M. Farid, R. Md. Ayob, and M. S. Py, "Utilizing sugarcane wasted fibers as a sustainable acoustic absorber," Procedia Engineering, vol. 53, pp. 632-638, 2013.

[12] L. P. Bastos, G. S. V. Melo, and N. S. Soeiro, "Panel manufactured from vegetable fibers: an alternative approach for controlling noises in indoor environments," Advances in Acoustics and Vibration, vol. 2012, Article ID 698737, 9 pages, 2012.

[13] D. J. Oldham, C. A. Egan, and R. D. Cookson, "Sustainable acoustic absorbers from the biomass," Applied Acoustics, vol. 72, no. 6, pp. 350-363, 2011.

[14] N. Childs, J. Dyck, and J. Hansen, "Southeast Asia projected to remain top rice exporter," Economic Research ServiceUnited States Department of Agriculture, http://www.ers.usda gov/amber-waves/2013-february/southeast-asia-projected-toremain-top-rice-exporter.aspx.

[15] S. Zafar, "Biomass resources from rice industry," Bioenergy consult, http://www.bioenergyconsult.com/biomass-resourcesrice-industry/.

[16] E. Natarajan, A. Nordin, and A. N. Rao, "Overview of combustion and gasification of rice husk in fluidized bed reactors," Biomass and Bioenergy, vol. 14, no. 5-6, pp. 533-546, 1998.

[17] O. P. Rupela, S. Gopalakrishnan, B. S. Sidhu, and V. Beri, "Composting rice straws in semi-arid condition," in Management of Crop Residues for Sustainable Crop Production, Technical Report, pp. 171-178, International Atomic Energy Agency, 2003.

[18] C. Huang, M. Zong, H. Wu, and Q. Liu, "Microbial oil production from rice straw hydrolysate by Trichosporon fermentans," Bioresource Technology, vol. 100, no. 19, pp. 4535-4538, 2009.

[19] T. L. Rost, "Rice anatomy: leaves," Rice-An anatomy atlas, http://www.plb.ucdavis.edu/labs/rost/Rice/Leaves/Leaves .html.

[20] H. S. Yang, D. J. Kim, and H. J. Kim, "Rice straw-wood particle composite for sound absorbing wooden construction materials," Bioresource Technology, vol. 86, no. 2, pp. 117-121, 2003.

[21] Y. Abdullah, A. Putra, H. Effendy, W. M. Farid, and M. R. Ayob, "Investigation on natural waste fibers from dried paddy straw as a sustainable acoustic absorber," in Proceedings of the 1st IEEE Conference on Clean Energy and Technology (CET '11), pp. 311314, Kuala Lumpur, Malaysia, June 2011.

[22] ISO 10534-2, "Acoustic-determination of sound absorption coefficient and impedance tubes-part 2: transfer function method," 2001.

[23] W. Su, X. M. Qian, X. Y. Li, and S. S. Liu, "Influence of thickness and density of nonwoven sound-absorbing material on the sound-absorption capability," Advanced Materials Research, vol. 197-198, pp. 440-443, 2011.

[24] M. J. Crocker and J. P. Arenas, "Use of sound absorbing materials," in Handbook of Noise and Vibration Control, M. J. Crocker, Ed., pp. 696-713, John Wiley \& Sons, Hoboken, NJ, USA, 2007.

[25] M. Long, Architectural Acoustic, Academic Press, New York, NY, USA, 2006. 

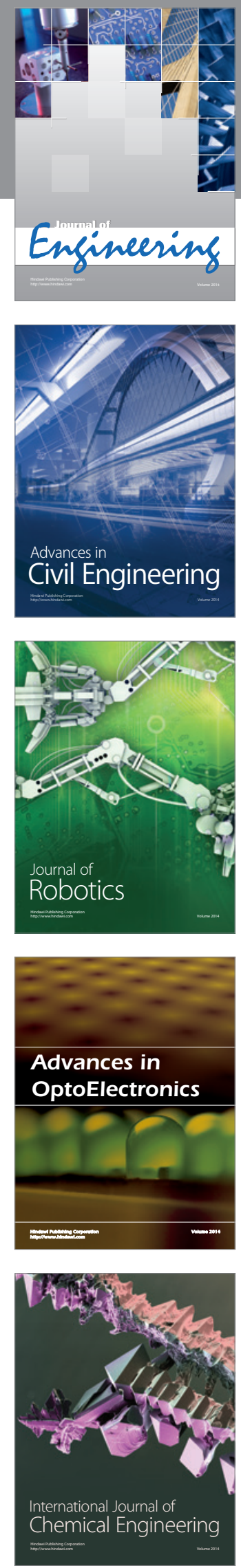

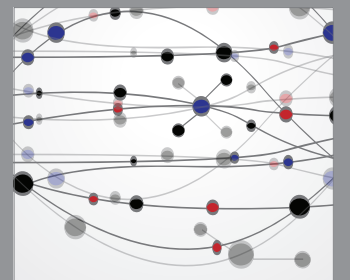

The Scientific World Journal
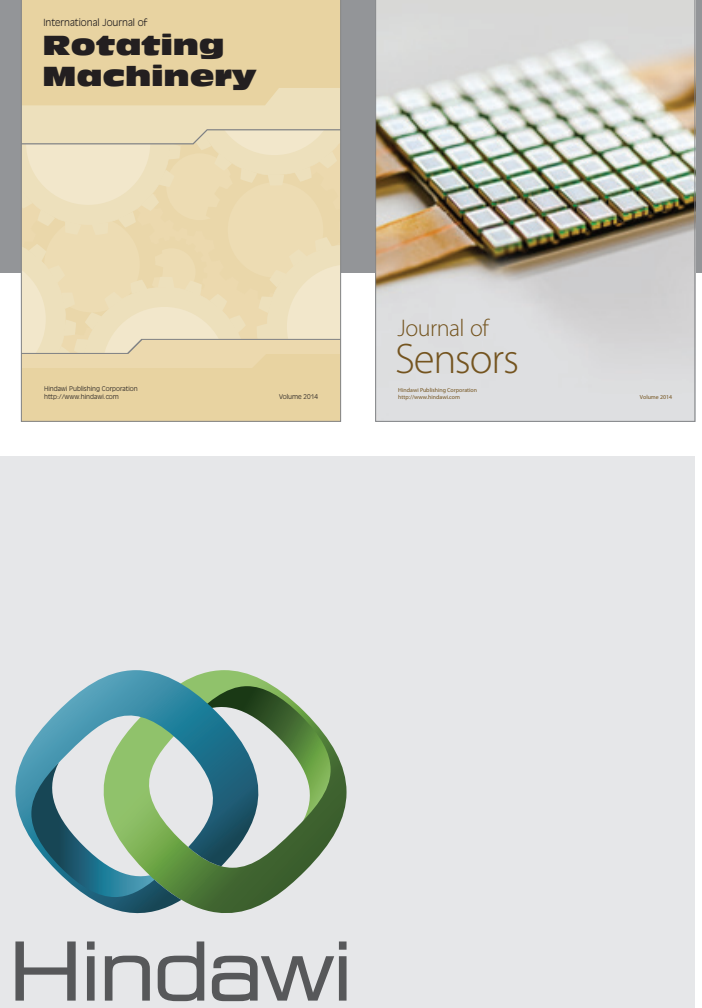

Submit your manuscripts at http://www.hindawi.com
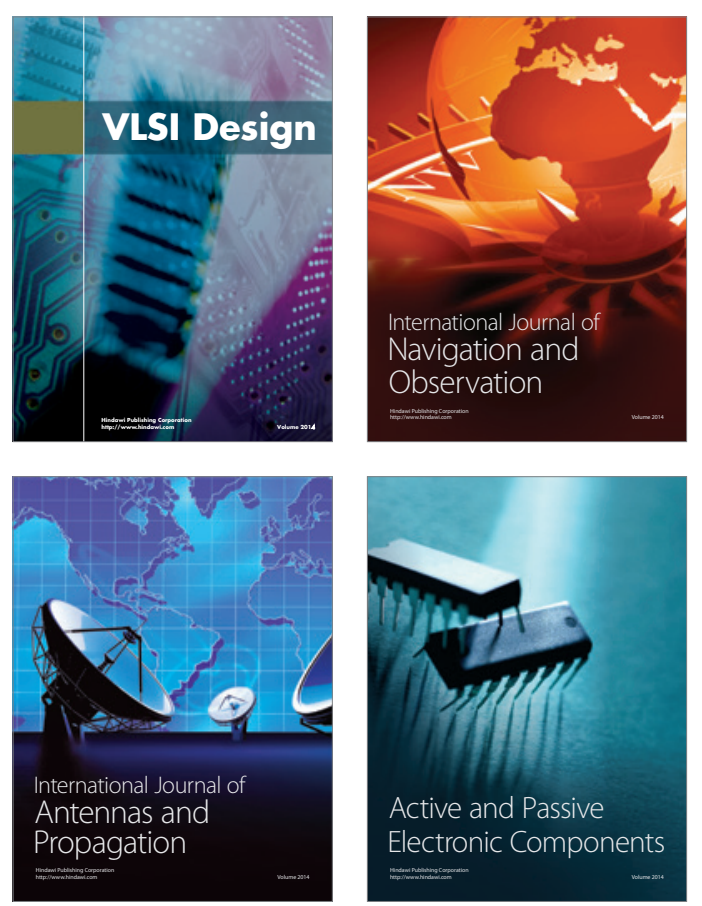
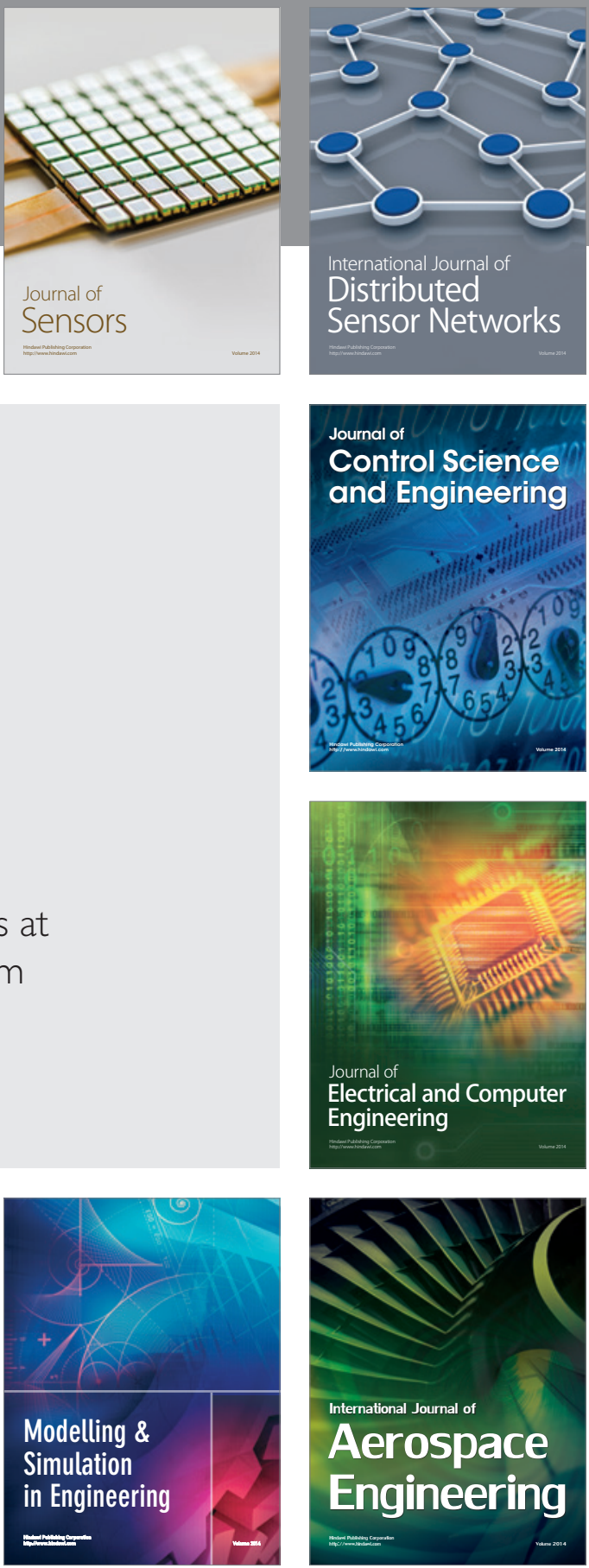

Journal of

Control Science

and Engineering
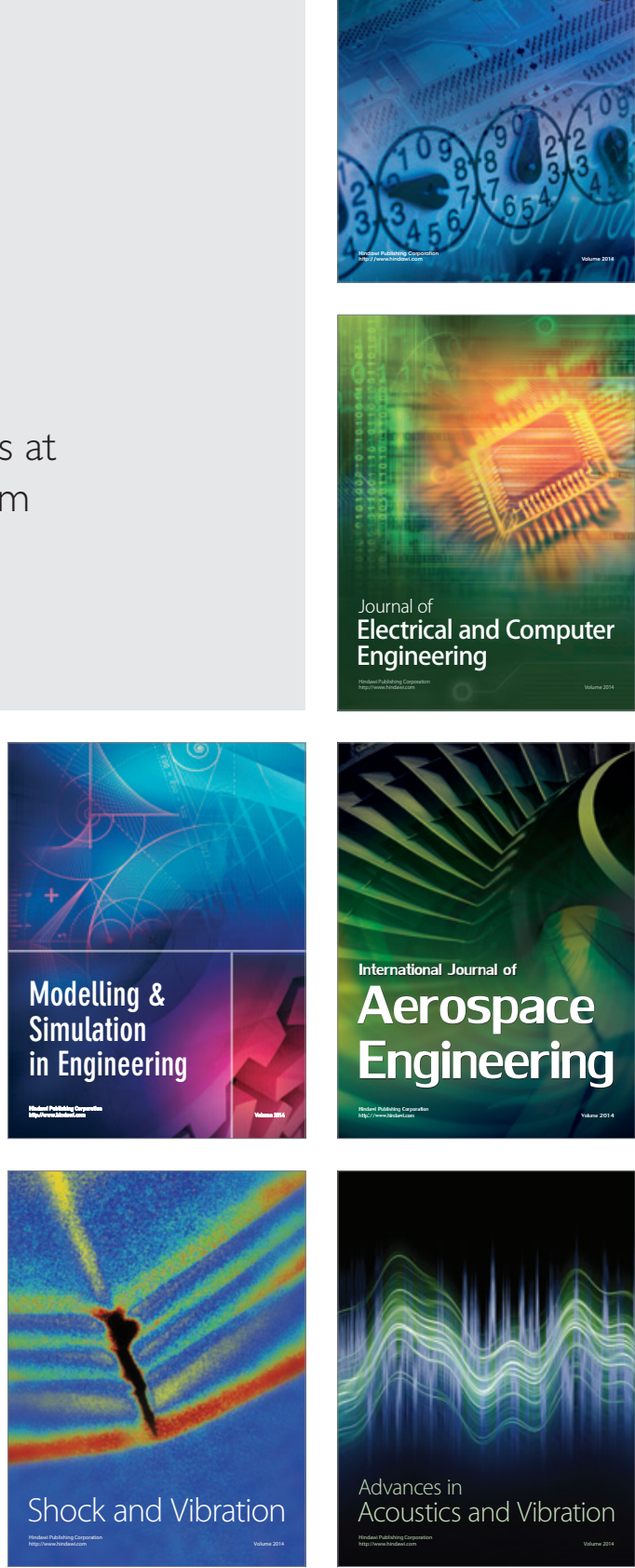